\title{
Clinical and Pathological Value of MACC-1 Expression in Gastric Carcinoma
}

\author{
Abeer Hafez ${ }^{1}$, Tarek El-Gohary ${ }^{2 *}$, Fouad Abutaleb ${ }^{2}$ \\ ${ }^{1}$ Pathology Department, Zagazig University Hospitals, Zagazig, Egypt \\ ${ }^{2}$ Medical Oncology and Hematology Department, Zagazig University Hospitals, Zagazig, Egypt \\ Email: *rania_ghonaim@yahoo.com
}

How to cite this paper: Hafez, A., El-Gohary, T. and Abutaleb, F. (2019) Clinical and Pathological Value of MACC-1 Expression in Gastric Carcinoma. Journal of Cancer Therapy, 10, 609-618. https://doi.org/10.4236/jct.2019.107050

Received: June 14, 2019

Accepted: July 26, 2019

Published: July 29, 2019

Copyright (c) 2019 by author(s) and Scientific Research Publishing Inc. This work is licensed under the Creative Commons Attribution International License (CC BY 4.0).

http://creativecommons.org/licenses/by/4.0/

(c) (i) Open Access

\begin{abstract}
Background: Gastric adenocarcinoma is known to be a markedly invasive disease with high potential for metastasis. Hepatocyte growth factor (HGF)/HGF receptor (MET) signaling pathway activation is an assumed mechanism of malignant transformation and metastatic potential of tumors. Metastasis associated with colon cancer-1 (MACC-1) has been identified as a key regulator of HGF/MET signaling. However, its role in gastric cancer is not well understood. Aim of this study is to assess the expression of MACC-1 in gastric cancer, its relation to other clinical and pathologic parameters and its impact on progression free and overall survival. Patient and Methods: Evaluation of MACC-1 protein expression by immune-histochemistry was done on paraffin-embedded tissues obtained from 46 patients with gastric cancer, where samples were taken from the tumor and adjacent normal mucosa. Results: MACC-1 was predominantly localized in the cytoplasm or membrane of the primary cancer cells. High MACC-1 expression was found in 63.1\% (29/46) of tumor samples, while MACC-1 expression was not detected in normal mucosa $(\mathrm{P}<0.01)$. Expression of MACC-1 was significantly associated with older age, larger tumor size, deeper tumor invasion, presence of lymph node metastasis, distant metastasis and advanced clinical stage $(\mathrm{p}<0.05)$, while no relation was found with gender, tumor location or histologic classification $(\mathrm{p}>0.05)$. Progression free and overall survival were significantly higher in patients with low MACC-1 expression compared to patients with high expression (Log Rank test, $\mathrm{p}=$ 0.02 and 0.04 , consequently). Conclusion: Our study found that MACC-1 expression is strongly related to gastric cancer stage and both progression free and overall survival, suggesting that MACC-1 promotes tumorigenesis and its expression may be used as signal of bad prognosis in gastric cancer.
\end{abstract}

\section{Keywords}

Gastric Cancer, MACC-1, HGF/MET Signaling 


\section{Introduction}

Gastric cancer is a highly lethal disease due to marked invasion and metastasis [1] [2]. The mechanism of tumor invasion and metastasis includes cell movement, adhesion, extracellular matrix degradation and angiogenesis [3] [4]. Biological markers associated with invasion and metastasis such as aberrant activation of the hepatocyte growth factor (HGF)/HGF receptor (MET) signaling pathway has been a focus for gastric cancer research [3] [5]. Distant organ metastasis is a signal of poor prognosis in patients with gastric cancer. Liver is a common target organ of gastric cancer metastasis [6]. Hepatic stellate cells (HSCs) are a type of liver-specific mesenchymal cells which are considered a main component of the prometastatic liver microenvironment. These cells can be activated by tumor-derived factors to stimulate the metastatic growth of tumor cells [7].

Metastasis-associated with colon cancer-1 (MACC-1) is a member of a family of soluble proteins. MACC1 hastens migration, invasion and metastasis of cancer cells through activating the hepatocyte growth factor (HGF)/MET proto-oncogene (c-Met) signaling pathway [8], together with provoking multiple cellular responses regulating cell morphogenesis, migration and breakdown of the extracellular matrix [9]. A study has previously demonstrated that the expression MACC1 is significantly higher in activated HSCs. MACC1 is reported to be associated with distant metastasis in gastric cancer [10]. Overexpression of MACC1 increases invasion in cancer cells by enhancing epithelial-mesenchymal transition (EMT) [11], and is significantly correlated to decreased overall survival (OS) and disease-free survival (DFS) [12].

MACC-1 was first identified during a genome wide search for genes differentially expressed in colorectal cancer [13]. However, the significance of MACC-1 expression and its impact on prognosis in gastric adenocarcinoma are still controversial

\section{Materials and Methods}

This study includes 46 gastric cancer patients who were diagnosed at Zagazig University Hospital in the period between February 2015 and January 2018. All patients with newly diagnosed gastric cancer during that time period were enrolled in the study provided they had normal cardiac, renal and hepatic functions and an ECOG performance status of $\leq 2$. Samples were taken with endoscopic biopsy from the gastric cancer tissue and adjacent normal gastric tissue more than $5 \mathrm{cms}$ from the margin. Samples were sent to the histopathology laboratory where they were formalin fixed and paraffin-embedded for histopathologic and immunohistochemical analysis. All patients were subjected to the following work-up; history and physical examination, complete blood counts, comprehensive chemistry profile, chest, abdomen \& pelvis CT scans with oral and IV contrast, nutritional assessment, family history screening. PET-CT, endoscopic ultrasound, MSI-H/dMMR, her-2 and PDL-1 testing were done when clinically indicated. Patients who were amenable for curative resection under- 
went surgery and those with unresectable locally advanced or metastatic disease received a two-drug combination (cisplatin $75-100 \mathrm{mg} / \mathrm{m}^{2} \mathrm{IV}$ over 3 hours on day 1 and fluorouracil $750-1000 \mathrm{mg} / \mathrm{m}^{2}$ IV continuous infusion over 24 hours daily on days $1-4$, cycled every 28 days or cisplatin $80 \mathrm{mg} / \mathrm{m}^{2} \mathrm{IV}$ over 3 hours on day 1 and capecitabine $1000 \mathrm{mg} / \mathrm{m}^{2}$ PO BID daily on days 1 - 14 cycled every 21 days. Trustuzumab was added for her-2 positive cases where a loading dose of $8 \mathrm{mg} / \mathrm{kg}$ IV on day 1 of cycle 1 was given followed by a maintenance dose of 6 $\mathrm{mg} / \mathrm{kg}$ IV every 21 days or a loading dose of $6 \mathrm{mg} / \mathrm{kg}$ IV on day 1 of cycle 1 followed by maintenance dose of $4 \mathrm{mg} / \mathrm{kg}$ IV every 14 days).

\section{Immunohistochemistry}

Immunohistochemical analysis was performed to study altered protein expression in 46 human gastric cancer and adjacent normal tissue samples, as previously described [14] [15]. Paraffin-embedded formalin-fixed tissue slides (4 $\mu \mathrm{m}$ ) were baked at $60^{\circ} \mathrm{C}$ for $2 \mathrm{~h}$, followed by deparaffinization with xylene, and rehydrated. Antigen retrieval was performed by submerging sections in EDTA antigenic retrieval buffer, and microwaving for $\mathrm{x}$ min. Sections were then treated with $3 \%(\mathrm{v} / \mathrm{v})$ hydrogen peroxide in methanol to quench endogenous peroxidase activity, followed by incubation with $1 \%(\mathrm{w} / \mathrm{v})$ bovine serum albumin to block non-specific binding. Sections were incubated with mouse monoclonal antibody againstMACC-1 and MET (Santa Cruz Biotechnology, 1:50 dilution) overnight at $4^{\circ} \mathrm{C}$. Normal goat serum was used as a negative control. After washing, tissue sections were treated with secondary antibody. Tissue sections were then counterstained with hematoxylin, dehydrated and mounted. A negative control slide was processed without primary antibody to detect any background staining or false-positive results.

MACC-1 was stained as buffy colored in the cytoplasm and/or membrane. Protein expression was assessed by two expert pathologists blinded to the clinical details.

Scoring was performed according to the percentage of stained cells observed

$0=\leq 5 \%$ of cells

$1=6 \%-25 \%$

$2=26 \%-50 \%$

$3=51 \%-100 \%$

An intensity score of “ 0 - 3 ” was also determined

0 = none,

1 = light yellow,

$2=$ yellow brown,

3 = brown) [16] [17] [18]

The final score was the product of the two former values

$0-1=-$

$2-3=+$

$4-5=++$

$6=+++$

Patients with a score of $-/+$ were classified as the low expression group, whe- 
reas those with $++/+++$ " were classified as the high expression group.

\section{Statistical Analysis}

Statistical analyses were performed using SPSS24.0 software. Measurement data were analyzed using the Student's $T$ test, while categorical data were studied using $\chi^{2}$ or Fisher exact test. Survival curves were estimated using the Kaplan-Meier method, and the log-rank test was used to compute differences between the curves. Statistical significance was set at $\mathrm{P}<0.05$.

Written informed consent was taken from all patients and study protocols were approved by the institutional review board at the faculty of medicine, $\mathrm{Za}$ gazig University.

\section{Results}

MACC-1 was predominantly localized in the cytoplasm or membrane of the primary cancer cells. High MACC-1expression was found in 63.1\% (29/46) of tumor samples, whileMACC-1 expression was not detected in normal mucosa ( $\mathrm{P}$ $<0.01$ ) (Figure 1).

Clinical \& pathological characteristics in relation to MACC-1 expression are presented in Table 1. The mean age of the patients was $53.2 \pm 11.9$. Patients with high MACC-1 expression were significantly older than those with low expression $(58.5 \pm 14.84$ vs $45.6 \pm 11.8 ; \mathrm{p}<0.05)$ with $67.4 \%$ being males and $32.6 \%$ females. MACC-1 high-expression was found in $81.5 \%$ (22/27) of tumors that were more than $5 \mathrm{cms}$ in size compared to only $36.8 \%$ (7/19) of tumors that were $<5 \mathrm{cms}(\mathrm{p}<0.05)$. Depth of invasion was found to be significantly associated with high MACC-1 expression as $82.1 \%$ (23/28) of T3 and T4 tumors had high

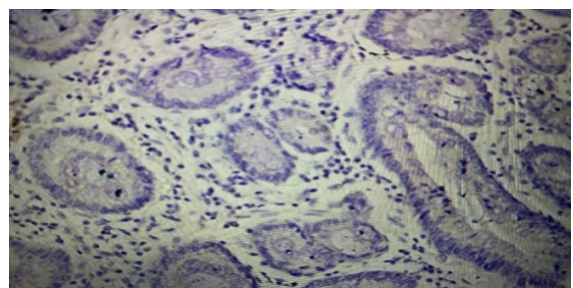

(A)

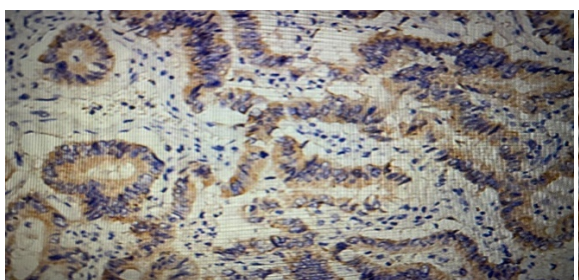

(C)

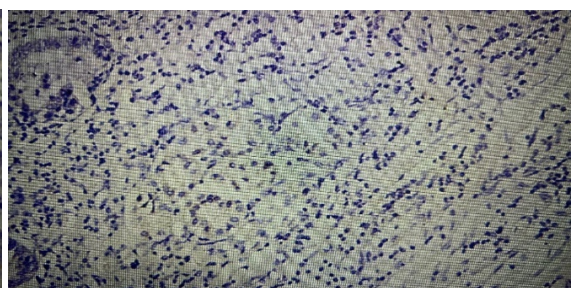

(B)

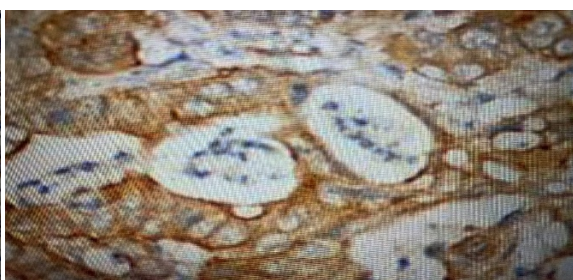

(D)

Figure 1. Immune-histo-chemical staining of MACC-1 in normal \& cancer tissue. (A) Negative immune-histo-chemical staining for MACC-1 in normal mucosa. (-) 200x; (B) Negative immune-histo-chemical staining for MACC-1 in gastric cancer tissue. (-) 200x; (C) Positive immune-histo-chemical staining for MACC-1 in gastric cancer tissue. $(++)$ 200x; (D) Positive immune-histo-chemical staining for MACC-1 in gastric cancer tissue. $(+++) 400 \times$. 
Table 1. Clinical \& pathological characteristics in relation to MACC-1 expression.

\begin{tabular}{|c|c|c|c|}
\hline Parameter & $\begin{array}{c}\text { Low MACC-1 } \\
\text { Expression } \\
n=17\end{array}$ & $\begin{array}{l}\text { High MACC-1 } \\
\text { Expression } \\
n=29\end{array}$ & $P$ value \\
\hline Age & $45.6 \pm 11.82$ & $58.5 \pm 14.84$ & $<0.05$ \\
\hline \multicolumn{4}{|l|}{ Gender } \\
\hline $\operatorname{Male}(\mathrm{n}=31)$ & $35.5 \%(11 / 31)$ & $64.5 \%(20 / 31)$ & \multirow{2}{*}{ NS } \\
\hline Female $(n=15)$ & $40 \%(6 / 15)$ & $60 \%(9 / 15)$ & \\
\hline \multicolumn{4}{|l|}{ Location } \\
\hline Cardia $(\mathrm{n}=9)$ & $33.3 \%(3 / 9)$ & $66.7 \%(6 / 9)$ & \multirow{3}{*}{ NS } \\
\hline Body $(\mathrm{n}=17)$ & $35.3 \%(6 / 17)$ & $64.7 \%(11 / 17)$ & \\
\hline Antrum $(\mathrm{n}=20)$ & $40 \%(8 / 20)$ & $60 \%(12 / 20)$ & \\
\hline \multicolumn{4}{|l|}{ Tumor size } \\
\hline$<5 \mathrm{~cm}(\mathrm{n}=19)$ & $63.2 \%(12 / 19)$ & $36.8 \%(7 / 19)$ & \multirow{2}{*}{$<0.05$} \\
\hline$\geq 5 \mathrm{~cm}(\mathrm{n}=27)$ & $18.5 \%(5 / 27)$ & $81.5 \%(22 / 27)$ & \\
\hline \multicolumn{4}{|l|}{ Histological classification } \\
\hline Papillary adenocarcinoma $(\mathrm{n}=7)$ & $28.6 \%(2 / 7)$ & $71.4 \%(5 / 7)$ & \multirow{4}{*}{ NS } \\
\hline Tubular adenocarcinoma $(\mathrm{n}=22)$ & $36.4 \%(8 / 22)$ & $63.6 \%(14 / 22)$ & \\
\hline Mucinous adenocarcinoma $(\mathrm{n}=8)$ & $37.5 \%(3 / 8)$ & $62.5 \%(5 / 8)$ & \\
\hline Signet-ring cell carcinoma $(n=9)$ & $44.4 \%(4 / 9)$ & $55.6 \%(5 / 9)$ & \\
\hline \multicolumn{4}{|l|}{ Invasion depth } \\
\hline $\mathrm{T} 1,2(\mathrm{n}=18)$ & $66.7 \%(12 / 18)$ & $33.3 \%(6 / 18)$ & \multirow{2}{*}{$<0.05$} \\
\hline $\mathrm{T} 3,4(\mathrm{n}=28)$ & $17.9 \%(5 / 28)$ & $82.1 \%(23 / 28)$ & \\
\hline \multicolumn{4}{|l|}{ LN involvement } \\
\hline $\mathrm{NO}(\mathrm{n}=14)$ & $71.4 \%(10 / 14)$ & $28.6 \%(4 / 14)$ & \multirow{2}{*}{$<0.05$} \\
\hline YES $(n=32)$ & $21.9 \%(7 / 32)$ & $78.1 \%(25 / 32)$ & \\
\hline \multicolumn{4}{|l|}{ Distant metastasis } \\
\hline $\mathrm{M} 0(\mathrm{n}=32)$ & $43.7 \%(16 / 32)$ & $50 \%(16 / 32)$ & \multirow{2}{*}{$<0.05$} \\
\hline $\mathrm{M} 1(\mathrm{n}=14)$ & $7.1 \%(1 / 14)$ & $92.9 \%(13 / 14)$ & \\
\hline \multicolumn{4}{|l|}{ TNM stages } \\
\hline I, II $(\mathrm{n}=16)$ & $68.7 \%(11 / 16)$ & $31.3 \%(5 / 16)$ & \multirow{2}{*}{$<0.05$} \\
\hline III, IV $(\mathrm{n}=30)$ & $20 \%(6 / 30)$ & $80 \%(24 / 30)$ & \\
\hline
\end{tabular}

MACC-1 expression compared to only 33.3\% (6/18) of T1 and T2 tumors ( $\mathrm{p}<$ 0.05). Seventy eight percent (25/32) of cases with positive LN metastasis had high MACC-1 expression compared to $28.6 \%$ (4/14) of cases with negative LN metastasis $(\mathrm{p}<0.05)$. High MACC-1 expression was found in 92.9\% (13/14) of patients with distant metastasis compared to $50 \%(16 / 32)$ of cases without metastasis $(\mathrm{p}<0.05)$. The percentage of patients with stages III and IV in whom MACC-1 was highly expressed $(80 \%, n=24 / 30)$ was significantly higher than 
that of patients with low expression $(20 \%, n=6 / 30)$. In contrast, MACC-1 expression showed no significant relation with gender, tumor location or histological classification.

\section{Survival analysis}

The median progression free survival for patient with low MACC-1 expression was 24 months (95\% CI; 11.86 - 31.47) compared to 15 months (95\% CI; 10.01 - 17.91) for patient with high MACC-1 expression. The median overall survival for patients with low MACC-1 expression was not reached, while that of patients with high expression was 17 months (95\% CI; 10.36 - 21.64).

Progression free and overall survival were significantly higher in patients with low MACC-1 expression compared to patients with high expression (Log Rank test, $\mathrm{p}=0.02$ and 0.04 , consequently) (Figure 2 ).

\section{Discussion}

In Egypt, gastric cancer is the $12^{\text {th }}$ most common cancer in both sexes representing $1.6 \%$ of the total cancers. It is the $12^{\text {th }}$ leading cause of cancer death representing $2.2 \%$ of the total cancer mortality. The median age of GC in the Egyptians is 56 years. The incidence rises with age and $55 \%$ of cases occur between 50 and 70 years of age [19].

A number of studies have shown that gastric cancer progression, invasion and metastasis are associated with distinct gene expression profiles [1] [20]. In order to identify genes differentially expressed in gastric cancer, gene expression in gastric cancer specimens and healthy tissues were profiled using microarrays. Four hundred thirty-four genes were identified of which, 169 expressed sequence tags (ESTs) that were up-regulated at least 2 folds in primary gastric carcinomas and of these, MACC-1 was found to be one of the most highly upregulated genes [19] [20]. In our study, we verified this microarray data by immune-histo-chemical analysis. We found that gastric cancer specimens expressed high levels of MACC-1,
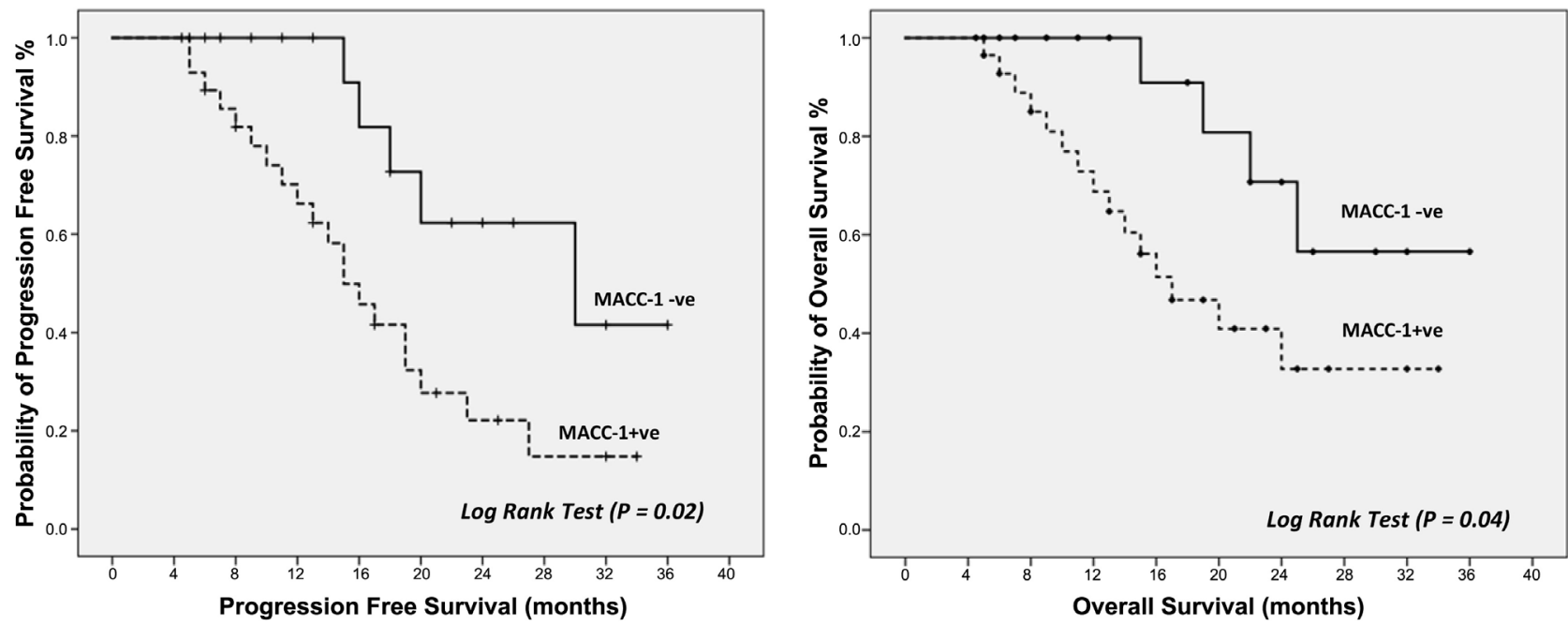

Figure 2. Progression free and overall survival. 
while normal gastric mucosa showed low MACC-1 expression. This adds a lot of value because its presence means at least that tissue is not normal. On the other hand, expression of MACC-1 immediately after surgery means incomplete removal of cancer. While its presence after means recurrence or new growth. This adds to importance of MACC-1 expression new dimension. These results are not identical to that of Duan et al., (2017), which showed low expression of MACC-1 in few cases of normal gastric tissue adjacent to cancer tissue. Actually, these results weaken the clinical value of MACC-1 expression because negative results may occur in cancer and positive expression may occur in normal tissue but we could explain these few cases by inaccurate sampling from tissues still not far enough from cancer tissues without clear safety margin. Even if these results were correct still high expression of MACC-1 carry the hope of being valuable marker especially no one single case of normal gastric tissues showed high expression of MACC-1 only very weak expression. Importantly, in our study high MACC-1 expression was significantly correlated with more aggressive clinic-pathological features related to size, depth of invasion, lymph node and distant metastases. These findings match with the study done by Jie Ma et al. [3], which showed the same results. Another very valuable point, correlation with severity of the lesions which make value of MACC-1 expression extend to more than a diagnostic tool as in our study, high expression of MACC-1 was not significantly different among different histological pattern of gastric carcinoma such as papillary, tubular or other forms ( $p>0.05)$ but the situation is much different as regard clinical staging. There is very highly significant difference among patients in late stages (III, IV) as almost all the patient showed high expression (92.2\%) with exception only one patient in early stages (I, II) showed high expression. Such findings take MACC-1 expression to another dimension to be a severity marker and may be used for follow up or even therapy success marker.

These results supported by results of many studies [1] [3] [20] [21] [22]. but our results showed more strong correlation may be due to limited number of participants or nature of our samples from Egyptian patients with different race, gene profile, co-morbid conditions and bacterial flora. More interestingly, the progression free and overall survival were significantly higher in patients with low MACC-1 expression compared to patients with high expression $(\mathrm{p}=0.02$ and 0.04 , consequently). On the other hand, our study provide evidence that high expression of MACC-1 was significantly higher in primary tumors which developed lymph node metastasis, compared to those with no metastasis. These findings were considered as reasonable confirmatory results as presence of distant metastasis associated of course with bad prognosis and poor survival. These results were documented in previous study of Jia et al. (2013) which confirm the importance of MACC-1 as diagnostic and prognostic marker. The pathologic role of MACC-1 could be explained easily if we know that MACC-1 is a well identified key regulator of $\mathrm{HGF} / \mathrm{MET}$ signaling, strongly induces MET expres- 
sion and promotes tumor cell invasion and metastasis [6]. Aberrant activation of the hepatocyte growth factor (HGF)/HGF receptor (MET) signaling pathway is well known documented putative mechanism associated with both malignant transformation and metastatic potential of tumors [3] [5].

\section{Conclusion}

Our study found that MACC-1 expression is strongly related to gastric cancer stage and both progression free and overall survival, suggesting that MACC-1 promote tumorigenesis and its expression may be used as signal of bad prognosis in gastric cancer.

Limitation of the study includes limited patient number and lack of long term follow up that could be solved in future studies in order to increase the accuracy of statistics and add another dimension to MACC-1 as prognostic marker.

\section{Conflicts of Interest}

The authors declare no conflicts of interest regarding the publication of this paper.

\section{References}

[1] Duan, J., Chen, L., Zhou, M. and Liao, W. (2017) MACC1 Decreases the Chemosensitivity of Gastric Cancer Cells to Oxaliplatin by Regulating FASN Expression. Oncology Reports, 37, 2583-2592. https://doi.org/10.3892/or.2017.5519

[2] Smith, B.R. and Stabile, B.E. (2009) Extreme Aggressiveness and Lethality of Gastric Adenocarcinoma in the Very Young. The Archives of Surgery, 144, 506-510. https://doi.org/10.1001/archsurg.2009.77

[3] Ma, J., Ma, J., Meng, Q., Zhao, Z.-S. and Xu, W.-J. (2013) Prognostic Value and Clinical Pathology of MACC-1 and c-MET Expression in Gastric Carcinoma. Pathology \& Oncology Research, 19, 821-832. https://doi.org/10.1007/s12253-013-9650-0

[4] Okines, A.F., Reynolds, A.R. and Cunningham, D. (2011) Target in Angiogenesis in Esophagogastric Adenocarcinoma. Oncologist, 16, 844-858. https://doi.org/10.1634/theoncologist.2010-0387

[5] Lai, L. and Gold Schneider, I. (2001) Cutting Edge: Identification of a Hybrid Cytokine Consisting of IL-7 and the Beta-Chain of the Hepatocyte Growth Consisting of IL-7 and the Beta-Chain of the Hepatocyte Growth Factor/Scatter Factor. Immunology, 167, 3550-3554. https://doi.org/10.4049/jimmunol.167.7.3550

[6] Fock, K.M. (2014) Review Article: The Epidemiology and Prevention of Gastric Cancer. Alimentary Pharmacology \& Therapeutics, 40, 250-260. https://doi.org/10.1111/apt.12814

[7] Mikuriya, Y., Tashiro, H., Kuroda, S., Nambu, J., Kobayashi, T., Amano, H., Tanaka, Y. and Ohdan, H. (2015) Fatty Liver Creates a Pro-Metastatic Microenvironment for Hepatocellular Carcinoma through Activation of Hepatic Stellate Cells. International Journal of Cancer, 136, E3-E13. https://doi.org/10.1002/ijc.29096

[8] Stein, U., Dahlmann, M. and Walther, W. (2010) MACC1-More than Metastasis? Facts and Predictions about a Novel Gene. Journal of Molecular Medicine, 88, 
11-18. https://doi.org/10.1007/s00109-009-0537-1

[9] Sierra, J.R. and Tsao, M.S. (2011) c-MET as a Potential Therapeutic Target and Biomarker in Cancer. Therapeutic Advances in Medical Oncology, 3, S21-S35. https://doi.org/10.1177/1758834011422557

[10] Xie, Q.P., Xiang, C., Wang, G., Lei, K.F. and Wang, Y. (2016) MACC1 Upregulation Promotes Gastric Cancer Tumor Cell Metastasis and Predicts a Poor Prognosis. Journal of Zhejiang University Science B, 17, 361-366. https://doi.org/10.1631/jzus.B1500236

[11] Wang, L., Wu, Y., Lin, L., Liu, P., Huang, H., Liao, W., Zheng, D., Zuo, Q., Sun, L., Huang, N., et al. (2013) Metastasis-Associated in Colon Cancer 1 Upregulation Predicts a Poor Prognosis of Gastric Cancer, and Promotes Tumor Cell Proliferation and Invasion. International Journal of Cancer, 133, 1419-1430. https://doi.org/10.1002/ijc.28140

[12] Wang, G., Fu, Z. and Li, D. (2015) MACC1 Overexpression and Survival in Solid Tumors: A Meta-Analysis. Tumor Biology, 36, 1055-1065. https://doi.org/10.1007/s13277-014-2736-9

[13] Kokoszyńska, K., Kryński, J., Rychlewski, L., et al. (2009) Unexpected Domain Composition of MACC1 Links MET Signaling and Apoptosis. Acta Biochimica Polonica, 56, 317-323. https://doi.org/10.18388/abp.2009_2464

[14] Lang, A.H., Geller-Rhomberg, S., Winder, T., et al. (2012) A Common Variant of the MACC1 Gene Is Significantly Associated with Overall Survival in Colorectal Cancer Patients. BMC Cancer, 12, 20. https://doi.org/10.1186/1471-2407-12-20

[15] Lee, H.S., Cho, S.B., Lee, H.E., et al. (2007) Protein Expression Profiling and Molecular Classification of Gastric Cancer by the Tissue Array Method. Clinical Cancer Research, 13, 4154-4163. https://doi.org/10.1158/1078-0432.CCR-07-0173

[16] Mizokami, K., Kakeji, Y., Oda, S., et al. (2006) Clinicopathologic Significance of Hypoxia-Inducible Factor 1 Alpha Overexpression in Gastric Carcinomas. Journal of Surgical Oncology, 94, 149-154. https://doi.org/10.1002/jso.20568

[17] Song, L.B., Liao, W.T., Mai, H.Q., et al. (2006) The Clinical Significance of Twist Expression in Nasopharyngeal Carcinoma. Cancer Letters, 242, 258-265. https://doi.org/10.1016/j.canlet.2005.11.013

[18] Kolev, Y., Uetake, H., Iida, S., Ishikawa, T., Kawano, T. and Sugihara, K. (2007) Prognostic Significance of VEGF Expression in Correlation with COX-2, Micro-Vessel Density, and Clinicopathological Characteristics in Human Gastric Carcinoma. Annals of Surgical Oncology, 14, 2738-2747. https://doi.org/10.1245/s10434-007-9484-7

[19] Ferlay, J., Soerjomataram, I., Ervik, M., Dikshit, R., Eser, S. and Mathers, C. (2015) Cancer Incidence and Mortality Worldwide. International Journal of Cancer, 136, E359-E386. https://doi.org/10.1002/ijc.29210

[20] Xu, Z.Y., Chen, J.S. and Shu, Y.Q. (2010) Gene Expression Profile towards the Prediction of Patient Survival of Gastric Cancer. Biomedicine \& Pharmacotherapy, 64, 133-139. https://doi.org/10.1016/j.biopha.2009.06.021

[21] Lin, L., Huang, H., Liao, W., Ma, H., Liu, J., Wang, L., Huang, N., Liao, Y. and Liao, W. (2015) MACC1 Supports Human Gastric Cancer Growth under Metabolic Stress by Enhancing the Warburg Effect. Oncogene, 34, 2700-2710. https://doi.org/10.1038/onc.2014.204

[22] Sun, L., Duan, J., Jiang, Y., Wang, L., Huang, N., Lin, L., Liao, Y. and Liao, W. 
(2015) Metastasis-Associated in Colon Cancer-1 Upregulates Vascular Endothelial Growth Factor-C/D to Promote Lymphangiogenesis in Human Gastric Cancer. Cancer Letters, 357, 242-253. https://doi.org/10.1016/j.canlet.2014.11.035 